\title{
Metformin use and its effect on survival in diabetic patients with advanced non-small cell lung cancer
}

\author{
Oscar Arrieta ${ }^{1 *}$, Edgar Varela-Santoyo ${ }^{1}$, Enrique Soto-Perez-de-Celis², Roberto Sánchez-Reyes ${ }^{1}$,
} Martha De la Torre-Vallejo ${ }^{1}$, Saé Muñiz-Hernández ${ }^{1}$ and Andrés F. Cardona ${ }^{3,4}$

\begin{abstract}
Background: Previous population-based studies have demonstrated an association between metformin use and improved survival among diabetic patients with cancer. We sought to analyze the effects of diabetes and its treatment in terms of the survival of patients with lung cancer.

Methods: Overall, 1106 patients with non-small cell lung cancer (94.3\% with stage IV disease) were included. The outcomes were compared between the patients with $(n=186)$ and without diabetes $(n=920)$. The characteristics associated with antidiabetic treatment and proper glycemic control (defined as a mean plasma glucose $<130 \mathrm{mg} / \mathrm{dL}$ ) were examined at diagnosis. The overall survivals (OSs) of the different patient populations were analyzed using Kaplan-Meier curves, and a multivariate Cox proportional hazard model was used to determine the influences of the patient and tumor characteristics on survival.

Results: The OS for the entire population was 18.3 months (95\% Cl 16.1-20.4). There was no difference in the OSs of the diabetic and non-diabetic patients (18.5 vs 16.4 months, $p=0.62$ ). The diabetic patients taking metformin exhibited a superior OS than did those on other antidiabetic treatments (25.6 vs 13.2 months, $p=0.017$ ). Those with proper glycemic control had a better OS than did those without proper glycemic control and the non-diabetics (40.5 vs 13.2 and 18.5 months, respectively, $p<0.001$ ). Both the use of metformin (HR 0.53, $p<0.0001$ and HR $0.57, p=0.017$, respectively) and proper glycemic control (HR $0.49, p<0.0001$ and HR $0.40, p=0.002$, respectively) were significant protective factors in all and only diabetic patients, respectively.

Conclusions: The diabetic patients with proper glycemic control exhibited a better OS than did those without proper glycemic control and even exhibited a better OS than did the patients without diabetes mellitus. Metformin use was independently associated with a better OS.
\end{abstract}

Keywords: Diabetes mellitus, Carcinoma, Non-Small-Cell Lung, Metformin, Hypoglycemic agents

\footnotetext{
* Correspondence: ogar@unam.mx

This work was previously presented at the IASCL WCLC 2015 in Denver

Colorado in an oral presentation entitled: MINI29.04 - The Use of Metformin

and Proper Glycemic Control Are Associated with Improved Survival in

Non-Small Cell Lung Cancer Patients (Now Available) (ID 1612)

${ }^{1}$ Thoracic Oncology Unit and Laboratory of Personalized Medicine, Instituto

Nacional de Cancerología (INCan), Av. San Fernando 22 Col. Sección XVI,

Tlalpan, 14080 Mexico City, Mexico

Full list of author information is available at the end of the article
} 


\section{Background}

In Mexico, more than $95 \%$ of all patients with nonsmall cell lung cancer (NSCLC) present with advancedstage disease at the time of diagnosis [1]. Because the prevalence of type 2 diabetes is high both worldwide and in Mexico, it is very important to understand the effects of preexisting diabetes on the survival of patients with advanced NSCLC. The physiopathology of diabetes, the effects of its treatment and the changes in different organ systems observed in diabetic patients might be associated with clinical outcomes. Existing data regarding the effects of diabetes on NSCLC outcomes are conflicting. Although some early studies found longer survival rates in diabetic patients with NSCLC [2], this result was not confirmed in other larger series [3, 4]. Indeed, an elevated fasting glucose level was found to be independently associated with a significantly higher risk of mortality in patients with NSCLC [3].

Among the major hypoglycemic agents that are used for the treatment of diabetes, metformin has received the most attention regarding its potential antineoplastic uses. At the cellular level, metformin has profound effects on the mitochondrial respiration rate and the production of ATP [5]. Metformin affects multiple cellular pathways via the activation of AMP-activated protein kinase (AMPK) by liver kinase 1 (LKB1), which leads to decreases in growth factor signaling and proliferation via the inhibition of mTOR [6].

There is a general lack of information regarding the outcomes of diabetic patients with NSCLC who are treated with different antidiabetic agents, including metformin, and the published data come from large epidemiological databases that are prone to bias [7]. In this study, our objective was to analyze the effects of diabetes and its treatment in terms of the survival of patients with NSCLC.

\section{Methods}

We conducted a retrospective cohort observational study. Consecutive patients diagnosed with NSCLC at the Instituto Nacional de Cancerología (INCan) between January 2008 and December 2014 were retrieved from our electronic medical records. The study was approved by INCan's research committee (REV/05/16). Because the study was deemed as without risk, patient consent was not required. The patient and tumor characteristics, including age, comorbidities, body mass index, stage at diagnosis, tobacco use, wood smoke exposure and mutational analysis results, were obtained. All patients were staged using thoracic and abdominal CT scans, PET scans and MRI imaging of the central nervous system. Previous diagnoses of diabetes, current antidiabetic treatments and glucose measurements for each individual patient were also recorded at the time of the lung cancer diagnosis. The patients were considered to have a diagnosis of diabetes if they either fulfilled the American Diabetes Association (ADA) criteria for diabetes or were being treated with antidiabetic medications prior to diagnosis with NSCLC. The patients were treated according to published guidelines for the treatment of lung cancer [8]. Patients with missing data were excluded from the analysis.

Proper glycemic control was defined by a pre-prandial (fasting) glucose level of $70-130 \mathrm{mg} / \mathrm{dL}$ at the time of the lung cancer diagnosis, in accordance with the current guidelines of the ADA [9]. Because most patients lacked a measurement of glycated hemoglobin (HbA1C), we calculated the mean plasma glucose by averaging the patient's pre-prandial glucose measurements (at least 3). We considered patients with mean plasma glucose levels under $130 \mathrm{mg} / \mathrm{dL}$ to be within the proper glycemic control goals and those with a mean plasma glucose level over $130 \mathrm{mg} / \mathrm{dL}$ to have improperly controlled diabetes. The overall survival (OS) was calculated from the date of cancer diagnosis to the date of the last visit or death.

The de-identified patient dataset supporting the conclusions of this article is included within the article and its additional supporting file (Additional file 1).

\section{Statistical analysis}

For descriptive purposes, the continuous variables are summarized as arithmetic means with standard deviations (SD) and as medians with ranges. The categorical variables are summarized as the relative frequencies, proportions, and $95 \%$ confidence intervals (95\% CI). The Pearson chi-square test was used to compare the data between the diabetic and non-diabetic patients and between the patients with and without proper glycemic control. The OSs were analyzed using the Kaplan-Meier method, and comparisons between subgroups were performed using the log-rank test or the Breslow test. Statistically significant and borderline significant variables $(p<0.1)$ were included in a multivariate analysis. The Cox proportional hazards model was used to estimate the hazard ratios (HRs) and $95 \% \mathrm{CI}$. The variables that were included in the multivariate analysis were factors that are known to be associated with poor outcomes for patients with NSCLC (i.e., age, ECOG performance status, tumor stage, smoking status, epidermal growth factor receptor (EGFR) mutational status and metastatic disease). The variables of interest in the study (i.e., diagnosis of diabetes, mean plasma glucose and antidiabetic medications) and the variables that were found to be significant in the univariate analysis at the level of $p<0.01$ were also included in the model. The SPSS software package (version 22.0; SPSS, Chicago, IL, USA) was used for the data analysis. All $p$ values presented are two- 
sided, and $p$ values $<0.05$ were considered statistically significant.

\section{Results}

\section{Patient characteristics}

A total of 1106 patients with diagnoses of NSCLC were identified and considered eligible for the analysis. The median age was 61 years ( $\mathrm{SD} \pm 13$ years). Most of the patients were male (53\%) and had a history of smoking (58.8 \%). ECOG PSs of $0-1$ were observed in $75 \%$ of the patients, $68.2 \%$ of the patients had adenocarcinoma histologic diagnosis, and $94.3 \%$ were stage IV (M1a and M1b). Only 417 patients (37.7 \%) had undergone EGFR mutation testing, and 152 (36.5\%) of these patients were positive.

Diabetes was present in 186 (16.8 \%) of the patients at the time of cancer diagnosis. The characteristics of the diabetic and non-diabetic patients are presented and compared in Table 1. The calculated mean serum glucose was higher in the patients with diabetes than in the non-diabetics $(170 \mathrm{mg} / \mathrm{dL}[ \pm 78.5 \mathrm{mg} / \mathrm{dL}]$ vs $105 \mathrm{mg} / \mathrm{dL}$ $[ \pm 14.5 \mathrm{mg} / \mathrm{dL}], p<0.0001)$. There were no differences in stage, performance status, mutational status, smoking history or gender between the diabetic and non-diabetic patients. Metformin was used as an antidiabetic treatment at the time of diagnosis by $59.7 \%$ of the diabetic patients, and $31.4 \%$ were within the predefined definition of proper glycemic control (Table 2). Eighty-one percent $(n=150)$ of the diabetic patients had completed at least one line of treatment with either chemotherapy or tyrosine kinase inhibitors.

\section{Factors associated with survival in the overall cohort}

The median follow-up time was 10.8 months (0.6-111.1), and the median OS for the entire cohort was 18.3 months [95 \% CI 16.1-20.4]. The factors associated with OS are presented in Table 3. Female gender $(p<0.0001)$, no history of smoking $(p<0.01)$ and a lower stage at diagnosis $(p<0.0001)$ were associated with improved survival. Compared with the non-diabetic population, the patients with diabetes mellitus had a similar OS (18.5 vs. 16.4 months $p=0.619$, Fig. 1a). However, the patients with proper glycemic control exhibited a better OS (40.5 months [95 \% CI 11.2-69.8]) than did the diabetic patients without proper glycemic control (13.2 months [95 \% CI 12-14.4]) and even exhibited a better OS than did the patients without diabetes mellitus (18.5 months [95 \% CI 16.2-20.7]; Fig. 1b). Metformin use was associated with an improved OS in all of the patients, including the patients with and without diabetes mellitus (25.6 months [95 \% CI 13.7-37.6] vs 18.3 months [95\% CI 15.9-20.6], $p=0.046$; Fig. 1c). The factors that were independently associated with improved survival in the complete cohort are presented in Table 4 .
Table 1 Comparison of baseline characteristics between diabetic and non-diabetic patients

\begin{tabular}{|c|c|c|c|}
\hline \multirow[t]{2}{*}{ Characteristic } & $\begin{array}{l}\text { Non-diabetics } \\
(n=920)\end{array}$ & $\begin{array}{l}\text { Diabetics } \\
(n=186)\end{array}$ & \multirow[t]{2}{*}{$p$} \\
\hline & $\%(n / N)$ & $\%(n / N)$ & \\
\hline Gender & & & 0.44 \\
\hline Female & $47.2(434 / 920)$ & $46.2(86 / 186)$ & \\
\hline Male & $52.8(486 / 920)$ & $53.8(100 / 186)$ & \\
\hline Age at diagnosis (mean) & & & $<0.0001$ \\
\hline Mean (SD) & $51.2(13.1)$ & $64.5(10.5)$ & \\
\hline Smoking history & & & 0.22 \\
\hline Non-smoker & $40.7(374 / 920)$ & $44.1(82 / 186)$ & \\
\hline Smoker & $59.3(546 / 920)$ & $55.9(104 / 186)$ & \\
\hline Histology & & & 0.48 \\
\hline Adenocarcinoma & $68.3(628 / 920)$ & $67.7(126 / 186)$ & \\
\hline Other & $31.7(292 / 920)$ & $32.3(60 / 186)$ & \\
\hline Disease Stage & & & 0.36 \\
\hline$\|-\||| a$ & $5.5(51 / 920)$ & $6.5(12 / 186)$ & \\
\hline IIIb-IV & $94.5(869 / 920)$ & $93.5(174 / 186)$ & \\
\hline ECOG PS & & & 0.31 \\
\hline $0-1$ & $74.5(685 / 920)$ & $78(145 / 186)$ & \\
\hline $2-4$ & $25.5(235 / 920)$ & $22(41 / 186)$ & \\
\hline CNS metastases at diagnosis & & & 0.09 \\
\hline Absent & $53.5(492 / 920)$ & $47.8(89 / 186)$ & \\
\hline Present & $46.5(428 / 920)$ & $52.2(97 / 186)$ & \\
\hline Basal Glucose & & & $<0.0001$ \\
\hline Mean (SD) & $105(14.5)$ & $170(78.5)$ & \\
\hline EGFR mutation $(n=417)$ & & & 0.09 \\
\hline Positive & $34.9(123 / 352)$ & $44.6(29 / 65)$ & \\
\hline Negative & $65.1(229 / 352)$ & $55.4(36 / 65)$ & \\
\hline KRAS mutation $(n=184)$ & & & 0.60 \\
\hline Positive & 16.3. $(25 / 30)$ & $16.7(5 / 31)$ & \\
\hline Negative & $83.7(128 / 153)$ & $83.9(26 / 31)$ & \\
\hline
\end{tabular}

ECOG PS Eastern Cooperative Oncology Group Performance Status Score

Factors associated with survival in the diabetic patients

The univariate analyses revealed that the factors associated with improved OS in the diabetic patients were lower stage at diagnosis, the use of metformin and proper glycemic control (Table 3). Compared with the diabetic patients who were using other antidiabetic medications, the patients taking metformin exhibited a significantly better OS $(25.6$ [95 \% CI $13.7-37.6]$ vs 13.2 months [95 \% CI 11.9-14.5]; $p=0.017$, Fig. 1d). The largest improvement in OS was observed in the diabetic patients who achieved proper glycemic control (as defined by the calculated mean serum glucose; 40.5 vs 13.2 months; $\mathrm{p}<0.001)$. The diabetic patients with proper glycemic control exhibited a better OS than did 
Table 2 Treatment and glycemic control in the diabetic patient population $(N=186)$

\begin{tabular}{ll}
\hline Characteristic & Patients \% (n/N) \\
\hline Metformin & $59.7(111 / 186)$ \\
Yes & $40.3(75 / 186)$ \\
No & \\
Glibenclamide & $32.3(60 / 186)$ \\
Yes & $67.7(126 / 186)$ \\
No & \\
Insulin & $11.3(21 / 186)$ \\
Yes & $88.7(165 / 186)$ \\
No & \\
Other antidiabetic medication & $5.4(10 / 186)$ \\
Yes & $94.6(176 / 186)$ \\
No & \\
Basal Fasting Glucose & $170(78.5)$ \\
Mean $( \pm$ S.D. $)$ & $74-604$ \\
Range & \\
Glycemic Control $(n=185)^{\mathrm{a}}$ & $31.2(58 / 185)$ \\
Proper $\left(<130 \mathrm{mg} / \mathrm{dL}^{\mathrm{b}}\right)$ & $68.8(127 / 185)$ \\
Improper $\left(\geq 130 \mathrm{mg}^{\mathrm{d}} \mathrm{dL} \mathrm{b}^{\mathrm{b}}\right)$ &
\end{tabular}

${ }^{\text {a }}$ One patient with missing glucose values

${ }^{\mathrm{b}}$ Calculated mean serum glucose

both the poorly controlled diabetic patients and the non-diabetics (Fig. 1b). The multivariate analysis revealed that both the use of metformin (HR 0.57 [95\% CI $0.36-0.90] ; p=0.017)$ and proper glycemic control (HR $0.40[0.22-071] ; p=0.002)$ remained significant protective factors in the diabetic patient population (Table 4).

\section{Discussion}

Our results revealed that both the use of metformin and the maintenance of proper glycemic control are related to improved survival in the diabetic patients with advanced NSCLC. In our population, the use of metformin and the maintenance of proper glycemic control affected survival, independent of stage, histology and other antidiabetic treatments. Our results suggest that treatment with metformin, but not other hypoglycemic agents, is associated with a significant improvement in survival in patients with NSCLC and diabetes.

Evidence from epidemiological studies and metaanalyses has demonstrated associations of diabetes with several malignancies, including pancreatic [10], breast [11], prostate [12], colonic [13] and hepatocellular carcinomas [14]. In contrast, the relationship between diabetes and NSCLC is not well established, and epidemiological data have yielded conflicting results. Although some studies have reported an association between diabetes and NSCLC $[15,16]$, the majority has reported null or inverse relationships [17-19]. This potentially negative relationship is further illustrated by the fact that NSCLC has not been found to be associated with obesity, which is strongly related to the presence of diabetes [20]. Indeed, a high body mass index has been found to be a protective factor against NSCLC in some studies [21]. Further, a recently published meta-analysis by Zhang et al. concluded that metformin use in patients with diabetes appears to be associated with a reduced risk of lung cancer. This area requires further study and should be considered in the treatment of patients with diabetes and NSCLC [22].

The association between diabetes mellitus and survival in lung cancer patients is controversial [23] Whereas some studies suggest that patients with diabetes mellitus have worse prognoses due to comorbidities and disease complications that can be related to a reduced tolerance of treatment [24, 25], other studies have demonstrated that diabetic patients exhibited increased survival compared with non-diabetics [7, 26, 27]. The contradictory results between different studies might be the consequence of the analyses of heterogeneous populations. In the present study, we found that diabetes mellitus was not associated with an improved OS in all patients; however, our findings demonstrated that the diabetic patients with proper glycemic control exhibited a better OS than did the other diabetic patients and even the non-diabetics, which is consistent with previously published data [26].

Metformin has been explored as a pharmacological agent that may improve the survival of patients with several types of cancer. A recent meta-analysis reported associations between metformin and prolonged survival in patients with breast, colorectal, ovarian and endometrial cancers [28]. In NSCLC patients, the benefit of metformin on the prognosis has been demonstrated in large epidemiological studies [11] and in a meta-analysis [29]. Unfortunately, the main limitation of these studies is that they included heterogeneous patients and treatments and were thus prone to bias. In contrast, our report included a large set of NSCLC patients who were treated at a single reference institution where the prevalence of diabetes is high.

One potential explanation for the beneficial effects of metformin and proper glycemic control is that both are related to a reduction in circulating insulin levels. Insulin can stimulate both the insulin receptor (IR) and the insulin-like growth factor-1 receptor (IGF-1R), and both of these receptors are overexpressed in NSCLC patients and correlated with worse prognoses [30] and poor responses to targeted treatments [31]. Metformin has been demonstrated to interact with IGF signaling to reduce both the proliferation and migration of cancer cells [29]. There is a growing body of evidence regarding the 
Table 3 Overall survival and patient characteristics of the entire patient population $(n=1106)$ and the diabetic patient population $(n=186)$

\begin{tabular}{|c|c|c|c|c|c|c|}
\hline \multirow[b]{2}{*}{ Characteristic } & \multicolumn{3}{|c|}{ Entire Patient Population $(n=1106)$} & \multicolumn{3}{|c|}{ Diabetic Patient Population $(n=186)$} \\
\hline & $\begin{array}{l}\text { OS (m) } \\
\mathrm{n}\end{array}$ & $95 \% \mathrm{Cl}$ & $p$ & $\begin{array}{l}\text { OS (m) } \\
\mathrm{n}\end{array}$ & $95 \% \mathrm{Cl}$ & $p$ \\
\hline Gender & & & $<0.0001$ & & & 0.087 \\
\hline Female & $\begin{array}{l}23.0 \\
520\end{array}$ & $19.2-26.8$ & & $\begin{array}{l}26.9 \\
86\end{array}$ & $13.5-40.4$ & \\
\hline Male & $\begin{array}{l}14.9 \\
586\end{array}$ & $13-16.9$ & & $\begin{array}{l}14.3 \\
100\end{array}$ & $12-16.5$ & \\
\hline Age & & & 0.369 & & & 0.926 \\
\hline$\leq 61$ & $\begin{array}{l}18.7 \\
544\end{array}$ & $16.6-20.9$ & & $\begin{array}{l}16.4 \\
59\end{array}$ & $12.2-20.7$ & \\
\hline$>61$ & $\begin{array}{l}17.4 \\
562\end{array}$ & $12.8-22$ & & $\begin{array}{l}18.3 \\
127\end{array}$ & $7.3-29.2$ & \\
\hline Smoking history & & & 0.01 & & & 0.065 \\
\hline No & $\begin{array}{l}23.8 \\
456\end{array}$ & $20.1-27.4$ & & $\begin{array}{l}27.3 \\
82\end{array}$ & $22.8-31.9$ & \\
\hline Yes & $\begin{array}{l}15.2 \\
650\end{array}$ & $13.4-17$ & & $\begin{array}{l}13.8 \\
104\end{array}$ & $11.8-15.9$ & \\
\hline Histology & & & 0.089 & & & 0.678 \\
\hline Other & $\begin{array}{l}14.2 \\
352\end{array}$ & $11.1-17.2$ & & $\begin{array}{l}14.9 \\
60\end{array}$ & $10.3-19.6$ & \\
\hline Adenocarcinoma & $\begin{array}{l}20.2 \\
754\end{array}$ & $17.4-23$ & & $\begin{array}{l}16.4 \\
126\end{array}$ & $7.5-25.4$ & \\
\hline Stage & & & $<0.0001$ & & & 0.012 \\
\hline$\|-\| I \mid a$ & $\begin{array}{l}38.5 \\
63\end{array}$ & $17.3-59.7$ & & $\begin{array}{l}61.1 \\
12\end{array}$ & - & \\
\hline ||lb-IV & $\begin{array}{l}17.2 \\
1043\end{array}$ & $14.8-19.6$ & & $\begin{array}{l}15.2 \\
174\end{array}$ & $12.8-17.6$ & \\
\hline Diabetes & & & 0.619 & & & \\
\hline Yes & $\begin{array}{l}18.5 \\
186\end{array}$ & $16.2-20.7$ & & & & \\
\hline No & $\begin{array}{l}16.4 \\
920\end{array}$ & $8.3-24.5$ & & & & \\
\hline Metformin use & & & 0.046 & & & 0.017 \\
\hline No & $\begin{array}{l}18.3 \\
995\end{array}$ & $15.9-20.6$ & & $\begin{array}{l}13.2 \\
75\end{array}$ & $12.0-14.5$ & \\
\hline Yes & $\begin{array}{l}25.6 \\
111\end{array}$ & $13.7-37.6$ & & $\begin{array}{l}25.6 \\
111\end{array}$ & $13.7-37.6$ & \\
\hline Insulin use & & & 0.743 & & & 0.718 \\
\hline No & $\begin{array}{l}19 \\
1087\end{array}$ & $16.4-20.4$ & & $\begin{array}{l}17.0 \\
165\end{array}$ & $8.4-25.6$ & \\
\hline Yes & $\begin{array}{l}15.8 \\
19\end{array}$ & $8.6-22.9$ & & $\begin{array}{l}15.8 \\
21\end{array}$ & $8.6-23.0$ & \\
\hline Glibenclamide use & & & 0.703 & & & 0.473 \\
\hline No & $\begin{array}{l}18.4 \\
1046\end{array}$ & $16.4-20.5$ & & $\begin{array}{l}17.0 \\
126\end{array}$ & $5.2-28.7$ & \\
\hline Yes & $\begin{array}{l}15.2 \\
60\end{array}$ & $9.8-20.3$ & & $\begin{array}{l}15.2 \\
60\end{array}$ & $9.8-20.6$ & \\
\hline Glycemic control & & & $<0.001$ & & & $<0.0001$ \\
\hline Improper ( $\geq 130 \mathrm{mg} / \mathrm{dL}^{\mathrm{a}}$ ) & $\begin{array}{l}12.1 \\
208\end{array}$ & $10.1-14.1$ & & $\begin{array}{l}13.2 \\
127\end{array}$ & $12-14.4$ & \\
\hline Proper $\left(<130 \mathrm{mg} / \mathrm{dL}^{\mathrm{a}}\right)$ & $\begin{array}{l}19.8 \\
887\end{array}$ & $17.2-22.3$ & & $\begin{array}{l}40.5 \\
58\end{array}$ & $11.1-69.8$ & \\
\hline
\end{tabular}


Table 3 Overall survival and patient characteristics of the entire patient population $(n=1106)$ and the diabetic patient population $(n=186)$ (Continued)

\begin{tabular}{lll}
\hline Glycemic control and diabetes $^{\mathrm{b}}$ & & $<0.001$ \\
Proper diabetic control & 40.5 & $11.2-69.8$ \\
& 58 & \\
Improper diabetic control & 13.2 & $11.9-14.4$ \\
& 127 & $16.2-20.8$ \\
Non-diabetic & 18.4 & \\
\hline
\end{tabular}

OS Overall Survival, $m$ Months

${ }^{a}$ Calculated mean serum glucose ${ }^{b}$ One patient with missing glucose values

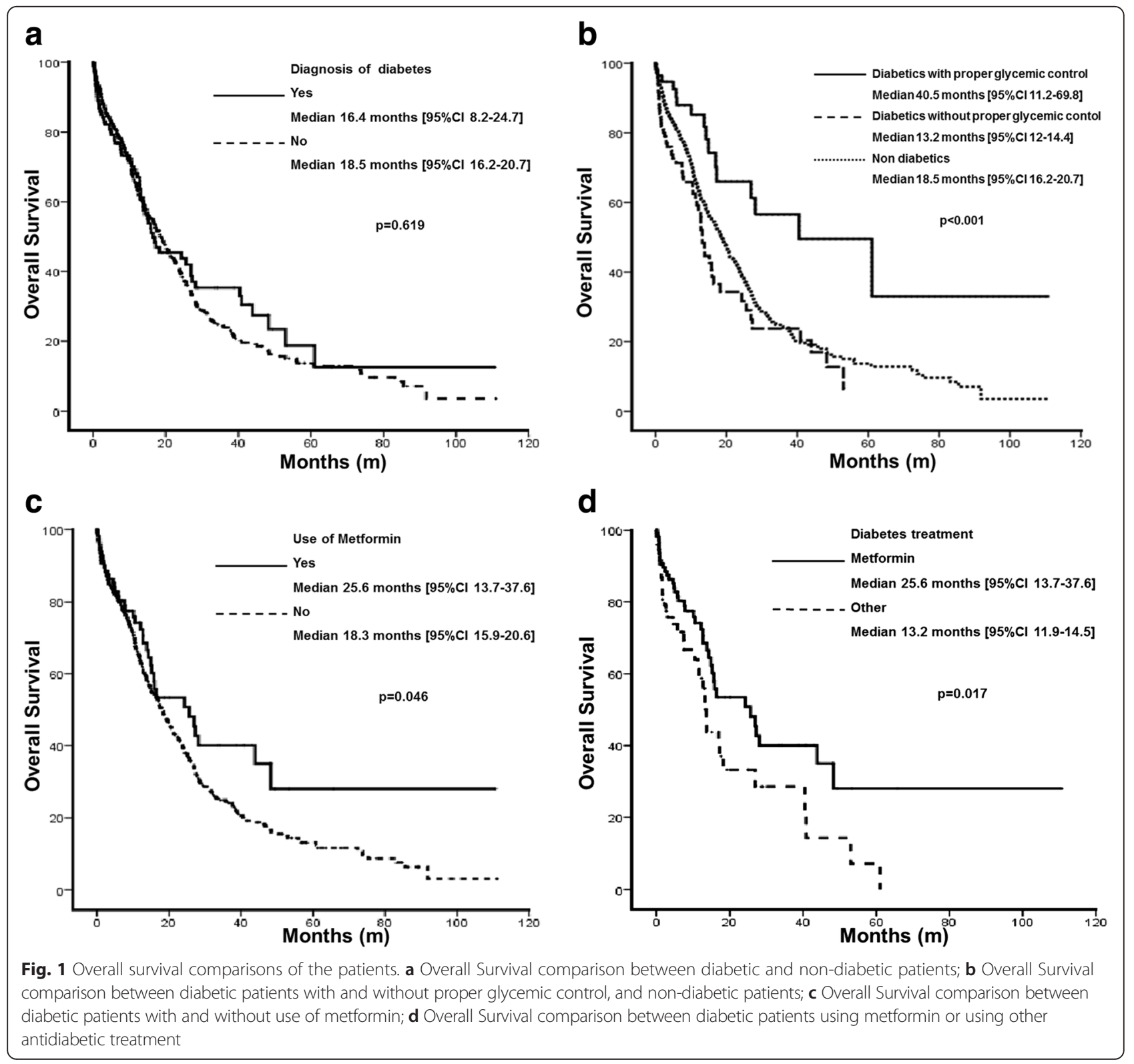


Table 4 Multivariate analysis of factors predicting survival in the entire patient population and in the diabetic patient population

\begin{tabular}{llll}
\hline Variable & \multicolumn{3}{l}{ All patients } \\
& HR & $95 \% \mathrm{Cl}$ & $P$ \\
Gender & 1.39 & $1.13-1.72$ & 0.002 \\
Smoking History & 1.18 & $0.95-1.44$ & 0.132 \\
Histology & 0.92 & $0.75-1.12$ & 0.421 \\
Clinical Stage IIIB-IV & 2.03 & $1.33-3.08$ & 0.001 \\
ECOG Performance Status & 1.26 & $1.10-1.43$ & 0.001 \\
Metformin use & 0.53 & $0.37-0.75$ & $<0.0001$ \\
Glycemic control & 0.49 & $0.39-0.63$ & $<0.0001$ \\
& & & \\
& Diabetic patient population & \\
& HR & $95 \% \mathrm{Cl}$ & $P$ \\
Gender & 1.36 & $0.80-2.33$ & 0.256 \\
Smoking History & 1.35 & $0.79-2.31$ & 0.277 \\
Clinical Stage IIIB-IV & 3.01 & $0.92-9.84$ & 0.068 \\
Metformin use & 0.57 & $0.36-0.90$ & 0.017 \\
Proper glycemic control & 0.40 & $0.22-0.71$ & 0.002 \\
\hline
\end{tabular}

effects of metformin on the multiple pathways that regulate carcinogenesis. Metformin inhibits mTOR translation initiation, the epithelial-mesenchymal transition (EMT), IL-6 secretion and STAT3 activity [32]. Thus, several preclinical experiments have tested combinations of metformin with radiotherapy [33], chemotherapy [34] and targeted therapies in lung cancer patients to overcome the mechanisms of resistance and to achieve synergy [35]. Metformin has been demonstrated to sensitize EGFR tyrosine kinase inhibitor (TKI)-resistant lung cancer cells by reversing the EMT and decreasing IL-6 signaling activation [32]. The combination of gefitinib (a reversible EGFR-TKI) and metformin induces a strong antiproliferative effect in NSCLC cell lines that harbor the wild-type LKB-1 gene [36]. Antiproliferative synergism between metformin and the multikinase inhibitor sorafenib via AMPK activation has also been demonstrated in NSCLC cells that harbor KRAS mutations [37]. Taken together, these data have led to the design of clinical trials utilizing combinations of metformin and targeted therapies for NSCLC patients who harbor specific mutations [38]. The ALMERA trial is an ongoing phase II trial conducted by the Ontario Clinical Oncology Group that will provide prospective evidence regarding the potential of metformin to improve the outcomes of standard cytotoxic therapy in locally advanced NSCLC patients [39].

Due to its retrospective nature, our study has some inherent limitations. HbA1c measurements were not available for the majority of the patients; therefore, we were unable to clearly identify patients with proper glycemic control. To resolve this issue, we calculated the mean plasma glucose levels using the fasting measurements from each patient. Although it was not ideal, this approach yielded the expected results in terms of the comparisons of the patient groups. Additionally, due to the retrospective nature of the data, we were unable to assess whether the patients who were not taking metformin had specific contraindications for its use or whether the patients with metformin prescriptions properly adhered to their treatment regimen. Furthermore, we had no data regarding whether patients who failed to achieve proper glycemic control were undergoing different types of treatment (e.g., chemotherapy rather than targeted therapy) that might have included high-dose steroids or had negative effects on proper adherence.

It is important to mention that our patients exhibited particularly prolonged average OS despite having advanced stage NSCLC. This finding may have resulted from the large incidence of EGFR-mutated tumors in our population $[40,41]$ and the broad access to clinical trials available at our institution. Some retrospective studies have associated the use of metformin with a lower risk of lung cancer, but the designs of these studies have been questioned due to time-related bias $[42,43]$. To reduce the risk of this bias, both metformin use and proper glycemic control were assessed at the time of the lung cancer diagnoses.

It is possible that patients undergoing cytotoxic chemotherapy rather than targeted therapy would be more likely to stop taking metformin or that the drug could have different effects depending on the mutational statuses of the patients. However, the small number of EGFR and KRAS patients taking metformin made it difficult to draw any conclusions regarding these particularly interesting populations.

Finally, we were unable to gather data about the related metabolic comorbidities, such as waist circumference and lipid levels. However, given that mortality in this patient population is mostly cancer-related, we believe that the influences of such comorbidities on outcome would be minimal.

\section{Conclusion}

The diabetic patients with proper glycemic control exhibited better OS than the diabetic patients without proper glycemic control and even exhibited better OS than did the patients without diabetes mellitus. Metformin use was independently associated with improved OS.

The use of metformin and the achievement of proper glycemic control have beneficial effects on the survival of patients with diabetes and advanced NSCLC. Prospective clinical trials of the use of metformin for lung cancer should be performed, particularly in selected populations in which the effects of metformin on signaling pathways could be potentially beneficial. 


\section{Additional file}

Additional file 1: Dataset supporting the conclusion of this article (XLSX $115 \mathrm{~kb}$ )

\section{Abbreviations}

ADA, American Diabetes Association; AMPK, AMP-activated protein kinase; Cl, confidence interval; EGFR, epidermal growth factor receptor; HbA1C, glycated hemoglobin; INCan, Instituto Nacional de Cancerología (Mexico City, Mexico); LKB1, liver kinase 1; NSCLC, Non-small cell lung cancer; OS, overall survival; $\mathrm{SD}$, standard deviations

\section{Acknowledgements \\ Not applicable}

\section{Funding}

Not Applicable

\section{Availability of data and materials}

The dataset supporting the conclusions of this article is included within the article and its supplementary files.

\section{Authors' contributions}

OA, EVS and MTV conceived and designed the study. OA, AFC, ESPC, SMH and EVS drafted the manuscript. All authors critically revised the manuscript. EVS, RSR, and MTV were in charge of data acquisition. All authors made substantial contributions to the analysis, and interpretation of data. All authors have read and approved the final manuscript.

\section{Competing interests}

The authors declare that they have no competing interests.

\section{Consent for publication}

Not applicable.

\section{Ethics approval and consent to participate}

This study was approved by the research committee at the Instituto Nacional de Cancerología (REV/05/16). Because the study was deemed as without risk, including only capture of data, approval for consent was waived.

\section{Author details}

${ }^{1}$ Thoracic Oncology Unit and Laboratory of Personalized Medicine, Instituto Nacional de Cancerología (INCan), Av. San Fernando 22 Col. Sección XVI, Tlalpan, 14080 Mexico City, Mexico. ${ }^{2}$ Cancer Care in the Elderly Clinic, Department of Geriatrics, Instituto Nacional de Ciencias Médicas y Nutrición Salvador Zubirán, Mexico City, Mexico. ${ }^{3}$ Clinical and Translational Oncology Group, Institute of Oncology, Clínica del Country, Bogotá, Colombia. ${ }^{4}$ Foundation for Clinical and Applied Cancer Research - FICMAC, Bogotá, Colombia

Received: 11 September 2015 Accepted: 1 August 2016 Published online: 12 August 2016

\section{References}

1. Arrieta O, Ramirez-Tirado LA, Baez-Saldana R, Pena-Curiel O, Soca-Chafre G, Macedo-Perez EO. Different mutation profiles and clinical characteristics among Hispanic patients with non-small cell lung cancer could explain the "Hispanic paradox". Lung Cancer. 2015;90(2):161-6.

2. De Giorgio R, Barbara G, Cecconi A, Corinaldesi R, Mancini AM. Diabetes is associated with longer survival rates in patients with malignant tumors. Arch Intern Med. 2000;160(14):2217

3. Luo J, Chen YJ, Chang LJ. Fasting blood glucose level and prognosis in non-small cell lung cancer (NSCLC) patients. Lung Cancer. 2012;76(2):242-7.

4. Satoh $H$, Ishikawa $H$, Kurishima $K$, Ohtsuka M, Sekizawa K. Diabetes is not associated with longer survival in patients with lung cancer. Arch Intern Med. 2001;161(3):485.

5. Rena G, Pearson ER, Sakamoto K. Molecular mechanism of action of metformin: old or new insights? Diabetologia. 2013;56(9):1898-906.
6. Sakoda LC, Ferrara A, Achacoso NS, Peng T, Ehrlich SF, Quesenberry Jr CP, Habel LA. Metformin use and lung cancer risk in patients with diabetes. Cancer Prev Res. 2015;8(2):174-9.

7. Lin JJ, Gallagher EJ, Sigel K, Mhango G, Galsky MD, Smith CB, LeRoith D, Wisnivesky JP. Survival of patients with stage IV lung cancer with diabetes treated with metformin. Am J Respir Crit Care Med. 2015;191(4):448-54.

8. Arrieta O, Guzman-de Alba E, Alba-Lopez LF, Acosta-Espinoza A, Alatorre-Alexander J, Alexander-Meza JF, Allende-Perez SR, Alvarado-Aguilar S, Araujo-Navarrete ME, Argote-Greene LM, et al. [National consensus of diagnosis and treatment of non-small cell lung cancer]. Rev Invest Clin. 2013;65 Suppl 1:S5-84

9. American Diabetes A. Standards of medical care in diabetes-2014. Diabetes Care. 2014:37 Suppl 1:S14-80.

10. Ben Q, Xu M, Ning X, Liu J, Hong S, Huang W, Zhang H, Li Z. Diabetes mellitus and risk of pancreatic cancer: A meta-analysis of cohort studies. Eur J Cancer. 2011;47(13):1928-37.

11. Larsson SC, Mantzoros CS, Wolk A. Diabetes mellitus and risk of breast cancer: a meta-analysis. Int J Cancer. 2007;121(4):856-62.

12. Kasper JS, Liu Y, Giovannucci E. Diabetes mellitus and risk of prostate cancer in the health professionals follow-up study. Int J Cancer. 2009:124(6):1398-403.

13. Larsson SC, Orsini N, Wolk A. Diabetes mellitus and risk of colorectal cancer: a meta-analysis. J Natl Cancer Inst. 2005;97(22):1679-87.

14. Wang C, Wang X, Gong G, Ben Q, Qiu W, Chen Y, Li G, Wang L. Increased risk of hepatocellular carcinoma in patients with diabetes mellitus: a systematic review and meta-analysis of cohort studies. Int J Cancer. 2012;130(7):1639-48.

15. Chodick G, Heymann AD, Rosenmann L, Green MS, Flash S, Porath A, Kokia E, Shalev V. Diabetes and risk of incident cancer: a large population-based cohort study in Israel. Cancer Causes Control. 2010;21(6):879-87.

16. Jee $\mathrm{SH}$, Ohrr H, Sull JW, Yun JE, Ji M, Samet JM. Fasting serum glucose level and cancer risk in Korean men and women. Jama. 2005;293(2):194-202.

17. Atchison EA, Gridley G, Carreon JD, Leitzmann MF, McGlynn KA. Risk of cancer in a large cohort of U.S. veterans with diabetes. Int J Cancer. 2011:128(3):635-43.

18. Hall GC, Roberts CM, Boulis M, Mo J, MacRae KD. Diabetes and the risk of lung cancer. Diabetes Care. 2005;28(3):590-4.

19. Yang WS, Yang Y, Yang G, Chow WH, Li HL, Gao YT, Ji BT, Rothman N, Zheng $\mathrm{W}$, Shu $\mathrm{XO}$, et al. Pre-existing type 2 diabetes and risk of lung cancer: a report from two prospective cohort studies of 133024 Chinese adults in urban Shanghai. BMJ Open. 2014:4(7):e004875.

20. Arnold M, Pandeya N, Byrnes G, Renehan AG, Stevens GA, Ezzati M, Ferlay J, Miranda JJ, Romieu I, Dikshit $\mathrm{R}$, et al. Global burden of cancer attributable to high body-mass index in 2012: a population-based study. Lancet Oncol. 2015:16(1):36-46.

21. Yang $Y$, Dong J, Sun $K$, Zhao L, Zhao F, Wang L, Jiao $Y$. Obesity and incidence of lung cancer: a meta-analysis. Int J Cancer. 2013;132(5):1162-9.

22. Zhang ZJ, Bi Y, Li S, Zhang Q, Zhao G, Guo Y, Song Q. Reduced risk of lung cancer with metformin therapy in diabetic patients: a systematic review and meta-analysis. Am J Epidemiol. 2014;180(1):11-4

23. Menamin ÚC, Cardwell CR, Hughes CM, Murray LM. Metformin use and survival from lung cancer: A population-based cohort study. Lung Cancer. 2016;94:35-9.

24. Lin J, Carter CA, McGlynn KA, Zahm SH, Nations JA, Anderson WF, Shriver CD, Zhu K. A Prognostic Model to Predict Mortality among Non-Small-Cell Lung Cancer Patients in the U.S. Military Health System. J Thorac Oncol. 2015;10(12):1694-702.

25. Imai H, Kaira K, Mori K, Ono A, Akamatsu H, Matsumoto S, Taira T, Kenmotsu $\mathrm{H}$, Harada $\mathrm{H}$, Naito $T$, et al. Prognostic significance of diabetes mellitus in locally advanced non-small cell lung cancer. BMC Cancer. 2015;15(1):989.

26. Hatlen $\mathrm{P}$, Gronberg BH, Langhammer A, Carlsen SM, Amundsen T. Prolonged survival in patients with lung cancer with diabetes mellitus. J Thorac Oncol. 2011:6(11):1810-7.

27. Tian RH, Zhang YG, Wu Z, Liu X, Yang JW, Ji HL. Effects of metformin on survival outcomes of lung cancer patients with type 2 diabetes mellitus: a meta-analysis. Clin Transl Oncol. 2016;18(6):641-9. doi:10.1007/s12094-0151412-x. Epub 2015 Oct 12.

28. Zhang ZJ, Li S. The prognostic value of metformin for cancer patients with concurrent diabetes: a systematic review and meta-analysis. Diabetes Obes Metab. 2014;16(8):707-10.

29. Sarfstein R, Friedman Y, Attias-Geva Z, Fishman A, Bruchim I, Werner $\mathrm{H}$. Metformin downregulates the insulin/IGF-I signaling pathway and inhibits 
different uterine serous carcinoma (USC) cells proliferation and migration in p53-dependent or -independent manners. PLoS One. 2013;8(4):e61537.

30. Kim JS, Kim ES, Liu D, Lee JJ, Solis L, Behrens C, Lippman SM, Hong WK, Wistuba II, Lee HY. Prognostic impact of insulin receptor expression on survival of patients with nonsmall cell lung cancer. Cancer. 2012;118(9):2454-65.

31. Yeo CD, Park KH, Park CK, Lee SH, Kim SJ, Yoon HK, Lee YS, Lee EJ, Lee KY, Kim TJ. Expression of insulin-like growth factor 1 receptor (IGF-1R) predicts poor responses to epidermal growth factor receptor (EGFR) tyrosine kinase inhibitors in non-small cell lung cancer patients harboring activating EGFR mutations. Lung Cancer. 2015;87(3):311-7.

32. Li L, Han R, Xiao H, Lin C, Wang Y, Liu H, Li K, Chen H, Sun F, Yang Z, et al, Metformin sensitizes EGFR-TKI-resistant human lung cancer cells in vitro and in vivo through inhibition of IL-6 signaling and EMT reversal. Clin Cancer Res. 2014;20(10):2714-26.

33. Wang J, Xia S, Zhu Z. Synergistic effect of phenformin in non-small cell lung cancer (NSCLC) ionizing radiation treatment. Cell Biochem Biophys. 2015;71(2):513-8.

34. Uehara T, Mitsuhashi A, Tsuruoka N, Shozu M. Metformin potentiates the anticancer effects of cisplatin under normoxic conditions in vitro. Oncol Rep. 2015;33(2):744-50

35. Chen H, Yao W, Chu Q, Han R, Wang Y, Sun J, Wang D, Wang Y, Cao M, He $Y$. Synergistic effects of metformin in combination with EGFR-TKI in the treatment of patients with advanced non-small cell lung cancer and type 2 diabetes. Cancer Lett. 2015;369(1):97-102.

36. Morgillo F, Sasso FC, Della Corte CM, Vitagliano D, D'Aiuto E, Troiani T, Martinelli E, De Vita F, Orditura M, De Palma R, et al. Synergistic effects of metformin treatment in combination with gefitinib, a selective EGFR tyrosine kinase inhibitor, in LKB1 wild-type NSCLC cell lines. Clin Cancer Res. 2013;19(13):3508-19.

37. Groenendijk FH, Mellema WW, van der Burg E, Schut E, Hauptmann M, Horlings HM, Willems SM, van den Heuvel MM, Jonkers J, Smit EF, et al. Sorafenib synergizes with metformin in NSCLC through AMPK pathway activation. Int J Cancer. 2015;136(6):1434-44.

38. Fasano M, Della Corte CM, Capuano A, Sasso FC, Papaccio F, Berrino L, Ciardiello F, Morgillo F. A multicenter, open-label phase II study of metformin with erlotinib in second-line therapy of stage IV non-small-cell lung cancer patients: treatment rationale and protocol dynamics of the METAL trial. Clin Lung Cancer. 2015;16(1):57-9.

39. Tsakiridis T, Ellis P, Cutz JC, Pond G, Wierzbicki M, Kavsak P, Wright J. OCOG-ALMERA: A phase II trial investigating the ability of Metformin to chemo-radiosensitize and prevent recurrence in locally advanced (LA) non-small cell lung cancer (NSCLC). J Thorac Oncol. 2016;11(No. 2S):S50.

40. Arrieta O, Cardona AF, Martin C, Mas-Lopez L, Corrales-Rodriguez L, Bramuglia G, Castillo-Fernandez O, Meyerson M, Amieva-Rivera E, Campos-Parra AD, et al. Updated Frequency of EGFR and KRAS Mutations in NonSmall-Cell Lung Cancer in Latin America: The Latin-American Consortium for the Investigation of Lung Cancer (CLICaP). J Thorac Oncol. 2015;10(5):838-43.

41. Arrieta O, Cardona AF, Federico Bramuglia G, Gallo A, Campos-Parra AD, Serrano S, Castro M, Aviles A, Amorin E, Kirchuk R, et al. Genotyping non-small cell lung cancer (NSCLC) in Latin America. J Thorac Oncol. 2011;6(11):1955-9.

42. Hense HW, Geier AS. Re: "reduced risk of lung cancer with metformin therapy in diabetic patients: a systematic review and meta-analysis". Am J Epidemiol. 2014;180(11):1130-1.

43. Zhang ZJ. One author replies. Am J Epidemiol. 2014;180(11):1131-2.

\section{Submit your next manuscript to BioMed Central and we will help you at every step:}

- We accept pre-submission inquiries

- Our selector tool helps you to find the most relevant journal

- We provide round the clock customer support

- Convenient online submission

- Thorough peer review

- Inclusion in PubMed and all major indexing services

- Maximum visibility for your research

Submit your manuscript at www.biomedcentral.com/submit
Biomed Central 